\title{
Low-cost alternatives to estimate unsaturated soil shear strength parameters
}

\author{
Michael Bardanis $^{1, a}$ and Sofia Grifiza ${ }^{1}$ \\ ${ }^{1}$ Edafos Engineering Consultants S.A., Laboratory, 2 Therapion st., 10444 Athens, Greece
}

\begin{abstract}
The paper presents experimental results form unconfined compression and splitting tensile tests used in combination in order to estimate the cohesion intercept of unsaturated soils. Samples of five different soils in the form of slurry were subjected to various suction values using the axis translation technique in a pressure plate extractor and then these samples were removed and subjected to unconfined compression and splitting tensile tests. Mohr' circles for the two loading conditions were drawn and the tangents plotted in order to obtain the cohesion intercept for each soil and each suction. Cohesion intercept was then plotted against suction for each soil and the angle of shear strength increase due to suction increase was estimated and compared to the value of the angle of shearing resistance of the fully saturated soil. The method allowed insight into the evolution of unsaturated soil shear strength of slurried soils, and seems to be an interesting low-cost alternative compared to established controlled suction methods to estimate unsaturated shear strength, yet it is based on two assumptions: first that the failure envelope is linear in the range between zero vertical stress and the stress corresponding to unconfined compression loading, and second that the suction applied to the samples does not change significantly from the moment a sample is removed from the pressure plate extractor until it is subjected to loading. The former assumption seems a fair one given the range of stress involved; the latter was investigated by conducting an unconfined compression tests with suction measurement during loaded. This test indicated that the latter assumption is a fair one too.
\end{abstract}

\section{Introduction}

The shear strength of unsaturated soils is of importance in many engineering problems. Test methods allowing its measurement that have been established for saturated soils, have also been extended for unsaturated soils. Yet this usually ends in methods that are quite expensive, time-consuming and presently quite limited in very few research centres and even fewer industry partners. The paper presents a low-cost alternative to estimate unsaturated soil shear strength parameters. The method proposed combines the Mohr's circles obtained from unconfined compression and splitting tensile (brazilian) tests on samples of soils subjected to a suction value in a pressure extractor (or a controlled relative humidity chamber if one wishes to extend the range of applied suction values). The method makes two assumptions: first that suction does not change significantly during the loading tests, and second that the generalised MohrCoulomb failure criterion for unsaturated soils [1] is fairly linear in the range of stress involved in unconfined compression and splitting tensile tests. The latter assumption is used to extrapolate the tangent to the two Mohr's circles backwards to the zero vertical stress axis in order to obtain an estimate of the cohesion intercept corresponding to the suction value applied to the samples prior to loading. The paper discusses both assumptions by presenting tests on five different soils tested in slurry form, in one unconfined compression test with suction measurement during loading too in order to exhibit the validity of the first assumption as well.

\section{The soils tested}

The soils tested were the Corinth and Chalkoutsi Marls, the Parnitha weathered siltstone, the Maroussi Clay and the Skiros weathered Phyllite. Index properties, soilwater characteristic curves and results from unconfined and indirect tensile strength tests for the first four soils mentioned have already been reported [2]. In this paper, the same data for Skiros weathered Phyllite are also presented, along with the saturated shear strength measured for all five soils in slurry form by means of the direct shear test. Finally, the combination of unconfined compression and indirect tensile strength test results is presented and the results are compared to the fully saturated shear strength parameters of the soils.

The index properties of the soils are summarised in Table 1. The Corinth Marls are a very well-studied formation [3] through which the Corinth Canal was excavated in late $19^{\text {th }}$ century. Various experimental investigation programmes have been undertaken in order to investigate the properties of this material including the SWCC of the undisturbed marl and its recomposed

\footnotetext{
a Corresponding author: mbardanis@edafos.gr, lab@edafos.gr
} 
counterpart [4], where recomposed is the material consolidated from a slurry condition to a desired value of void ratio (preferably that of the undisturbed soil) and then unloaded to zero stress. The Chalkoutsi Marl is a formation found $35 \mathrm{~km}$ north of Athens. High, steep slopes are formed in the formation by sea erosion of their toe with occasional landslides occurring along the $5 \mathrm{~km}$ coast that the formation outcrops in the highest slopes. The SWCC of the undisturbed material and its recomposed counterpart have already been reported [5]. Parnitha weathered siltstone is found in mount Parnitha $30 \mathrm{~km}$ to the north of Athens close to the ground surface. Samples of Maroussi Clay came from boreholes drilled as part of a site investigation in the suburb of Maroussi in Athens close to the 2004 Olympic Games complex. Finally, samples of Skiros weathered phyllite came from a low road-cut in the north part of the island of Skiros, Greece.

\section{Experimental method}

The axis translation technique as applied in a Soilmoisture Equipment Corp. pressure extractor with $1500 \mathrm{kPa}$ air-entry value porous ceramic disks was used for matric suction control. Tests were performed on samples prepared in the form of slurry. All slurries were prepared at an initial water content of $1.5 \times \mathrm{w}_{\mathrm{L}}$ using deaired, deionised water, left for hydration for two days in a humidity chamber with occasional stirring in order to avoid sedimentation of coarser particles in the slurry and then placed for at least half an hour under vacuum for removal of air. Samples were placed in lubricated plastic tubes taped on the porous stone of the pressure extractor. Given that samples were slurries in their initial condition, volume decrease during their drying was large. Careful lubrication of the inner surfaces of the tubes was critical so as to avoid cracking of the samples during shrinkage as any inhibition of the diameter decrease by adhesion to the inner surface of the tubes resulted in cracking.

Regarding shear strength, direct shear tests were performed on all soils tested, with the samples in the form of slurries. Angles of shearing resistance measured are summarised in Table 1. The experimental points from the tests on samples yielding the highest and lowest angle of shearing resistance are shown in Fig. 1. The larger the plasticity of the soils (the smaller therefore the angle of shearing resistance), the larger was the scatter of experimental points as slurries were becoming progressively more and more difficult to handle, despite the $\mathrm{w}_{\mathrm{o}} / \mathrm{w}_{\mathrm{L}}$ ratio being the same for all soils. This often resulted in quantity of the material flowing out of the gap between the top cap and the cell (Fig. 2), creating problems summing up to the larger scatter observed for higher plasticity soils. The measurement of the angle of shearing resistance of the fully saturated soils was considered essential in order to interpret the unconfined compression and splitting tensile tests on the samples subjected to various values of suction. As shown in Fig. 3, Mohr's circles from these two types of tests were plotted for each suction and the tangent to the circles was drawn in order to obtain the cohesion intercept corresponding to the applied suction on the assumption that the shear strength
Table 1. Index properties of the soils tested.

\begin{tabular}{|c|c|c|c|c|c|c|}
\hline Soil & $\begin{array}{c}\text { Clay } \\
(\%)\end{array}$ & $\begin{array}{c}\text { Silt } \\
(\%)\end{array}$ & $\begin{array}{c}\mathbf{w}_{\mathbf{L}} \\
\mathbf{( \% )}\end{array}$ & $\mathbf{I}_{\mathbf{P}}$ & $\boldsymbol{\varphi}^{\prime}$ & $\mathbf{U S C S}$ \\
\hline $\begin{array}{c}\text { Corinth } \\
\text { Marl (CM) }\end{array}$ & 6.5 & 84.7 & 30.5 & 5.5 & 27.5 & $\mathrm{ML}$ \\
\hline $\begin{array}{c}\text { Chalkoutsi } \\
\text { Marl } \\
(\mathrm{ChM})\end{array}$ & 20.5 & 64.2 & 51 & 30 & 25.0 & $\mathrm{CH}$ \\
\hline $\begin{array}{c}\text { Parnitha } \\
\text { weathered } \\
\text { siltstone } \\
\text { (PWS) }\end{array}$ & 27.5 & 47.1 & 33 & 17 & 24.7 & $\mathrm{CL}$ \\
\hline $\begin{array}{c}\text { Maroussi } \\
\text { clay (MC) }\end{array}$ & 40.1 & 41.9 & 47 & 28 & 19.2 & $\mathrm{CL}$ \\
\hline $\begin{array}{c}\text { Skiros } \\
\text { weathered } \\
\text { phyllite } \\
\text { (SWP) }\end{array}$ & 1.3 & 71.6 & N.P. & 35.3 & $\mathrm{ML}$ \\
\hline
\end{tabular}

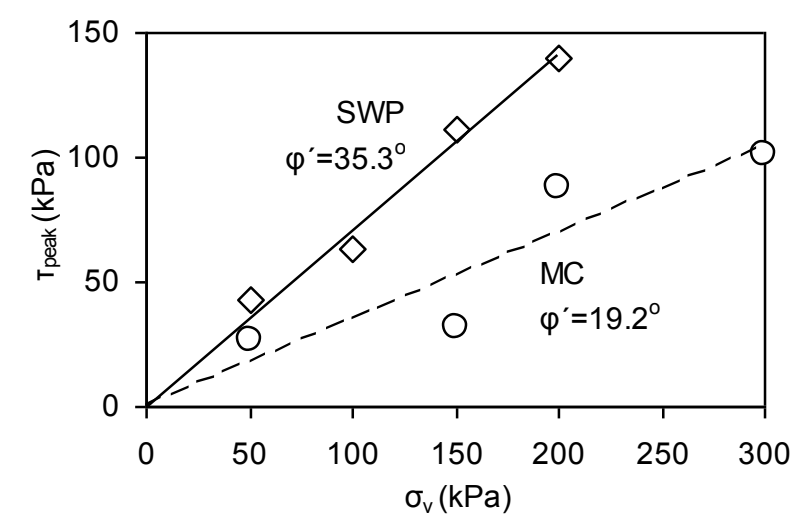

Figure 1. Shear strength versus vertical stress for Skiros weathered Phyllite (SWP, highest $\varphi^{\prime}$ ) and Maroussi Clay (MC, the soil with the lowest $\varphi^{\prime}$, and the largest variation in results).

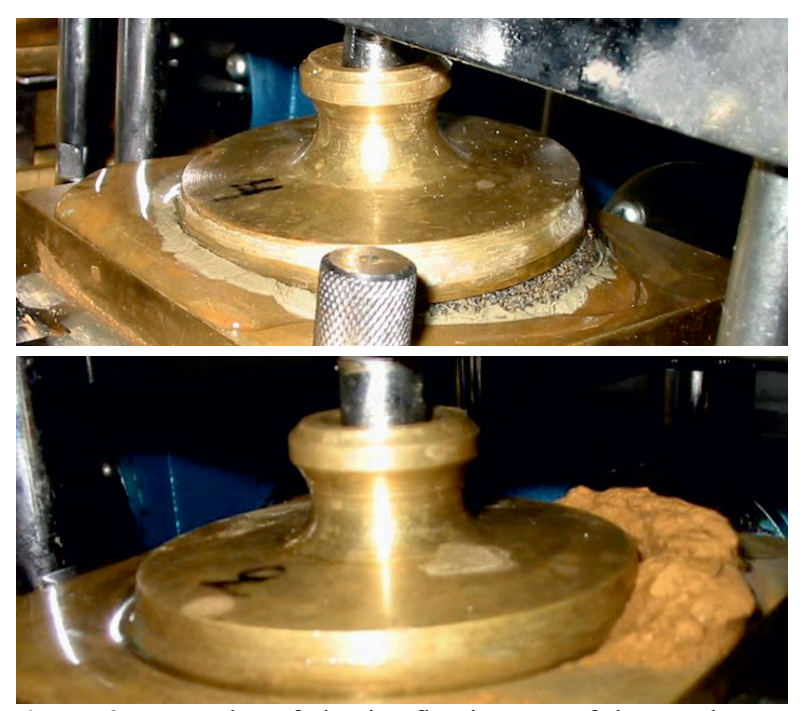

Figure 2. Examples of slurries flowing out of the gap between the top cap and the cell (top Chalkoutsi marl, bottom Maroussi clay). Tests with problems so severe were repeated.

envelope is linear. Mohr's circles for splitting tensile strength tests were plotted using established calculations for minimum and maximum stress during this type of loading condition [6]. The same tangent may be used to 


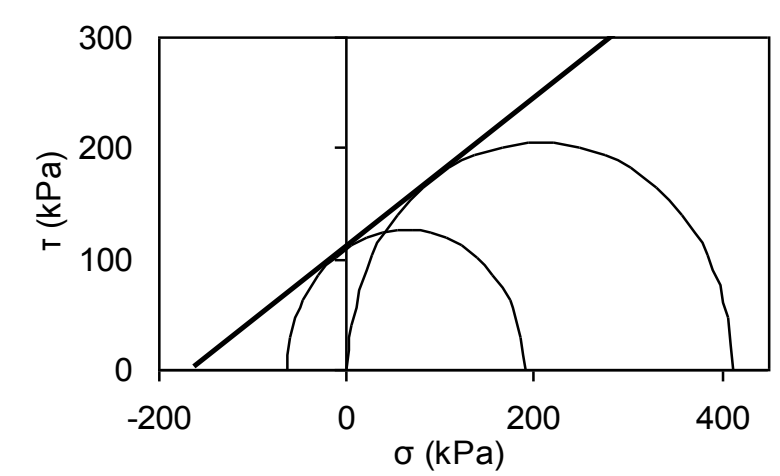

Figure 3. An example of the combination of Mohr's circles for splitting tensile test (circle on the left) and unconfined compression test (circle on the right) with the tangent to the two circles.

obtain the angle of shearing resistance; still as the two loading conditions (unconfined compression and splitting tensile loading) correspond to very low stress, these values were expected to be higher and were not used (it was only checked for each soil that they are higher than those in Table 1).

\section{Suction evolution investigation}

In order to investigate the assumption that suction does not change significantly from the time a sample is removed from the pressure plate extractor until the actual loading test is performed, one unconfined compression test was performed with an MPS-2 porous block frequency domain reflectometry (FDR) sensor (Decagon Devices, Inc.) installed in the sample (previously calibrated in the laboratory). A common tensiometer was initially considered as an option but it was finally rejected in favour of the MPS-2 as it has a limited range for measuring suction $(0-90 \mathrm{kPa})$ although admittedly is the instrument with the fastest response during suction measurement. Yet, as newer evidence [7] suggests that porous blocks have considerably fast response, the MPS2 sensor was selected for its greater range of suction measurement that allowed suctions to be applied that definitely lie beyond the air entry pressure of even the least plastic and coarser soil of those tested. This was the Skiros weathered Phyllite. A plastic tube was cut in order to install the MPS-2 sensor prior to placing the slurry of the soil in the tube (Fig. 4a \& c). The sensor was stabilised in position using plasteline and the inner surface of the tube was lubricated in order to minimise friction while the whole tube with the sensor was sealed on a metal plate again using plasteline. The whole array was placed on a scale for continuous monitoring of moisture loss due to evaporation and then the weathered phyllite slurry was poured into the tube and drying commenced (Fig. 4b). Once the sample dried enough to detach from the inner wall of the tube, the plastic tube was removed (Fig. 4c). Finally, when suction reached $520 \mathrm{kPa}$, the sample was lifted from the scale and taken to the loading frame for the loading under unconfined conditions to begin (Fig. 4d). Suction was monitored during the loading stage too. Axial stress vs axial strain is plotted in Fig. 5a and suction vs axial strain is plotted in Fig. 5b. It may be seen that the suction measured at the end of drying of $520 \mathrm{kPa}$ increased to only $524 \mathrm{kPa}$ at the beginning of the loading stage (approximately $20 \mathrm{~min}$ difference) and reached a maximum of $556 \mathrm{kPa}$ during the unconfined compression test. Even if one accepts that this is true increase of suction in the soil, it corresponds to only $7 \%$ increase in a non-plastic sandy silt. However it seems that this increase is not wholly due to soil drying but to cracking, allowing some air to come in contact with the sensor. As seen in Fig. 5a, a first yield occurred at $1.2 \%$ axial strain which corresponds to the initiation of
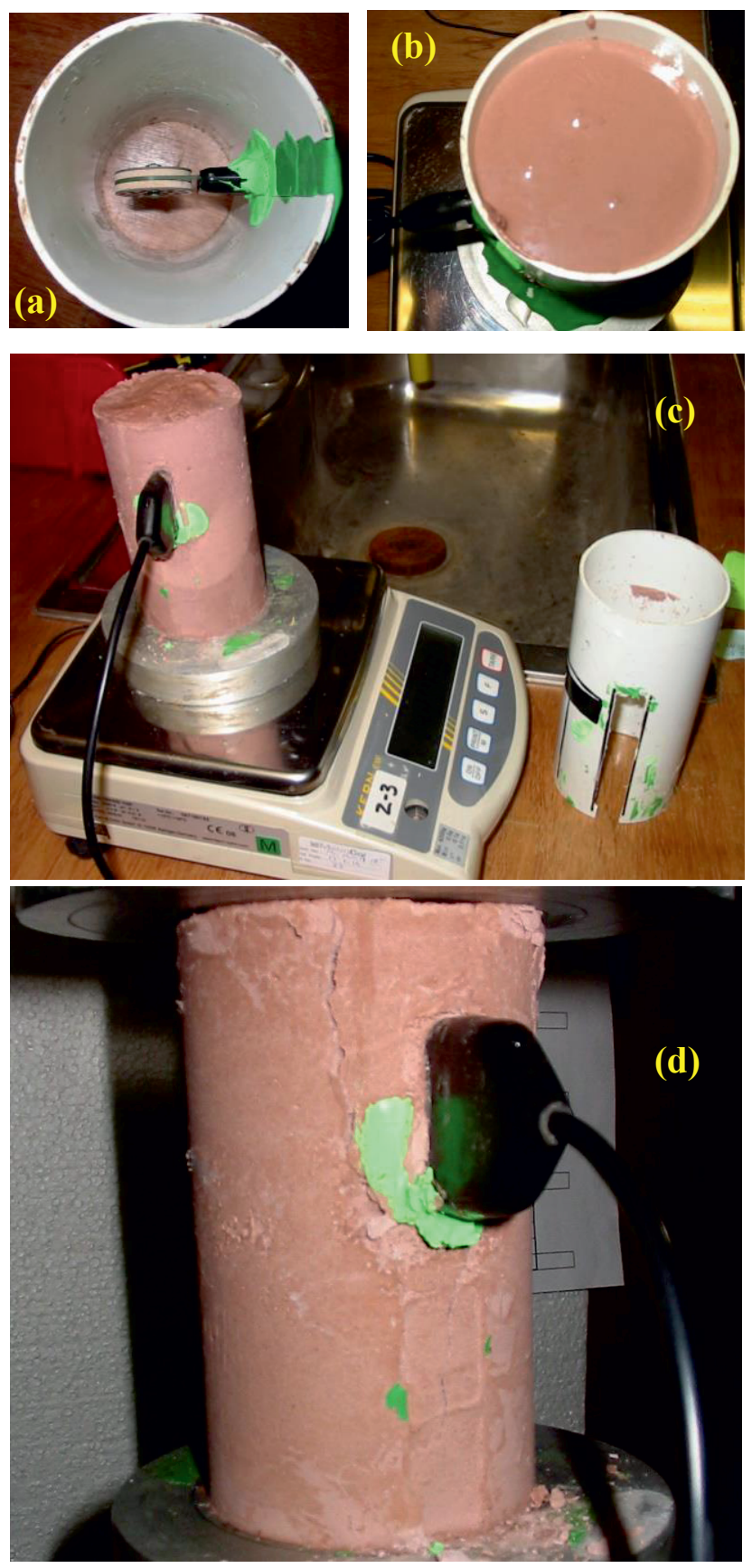

Figure 4. a) Empty plastic tube, cut to receive the MPS-2 sensor (green plasteline used to replace the part of the tube removed), b) same piece of tube filled with slurry of weathered phyllite, c) sample with the sensor installed after considerable drying had occurred that allowed removal of the plastic tube, and d) sample with sensor on the frame during loading. 

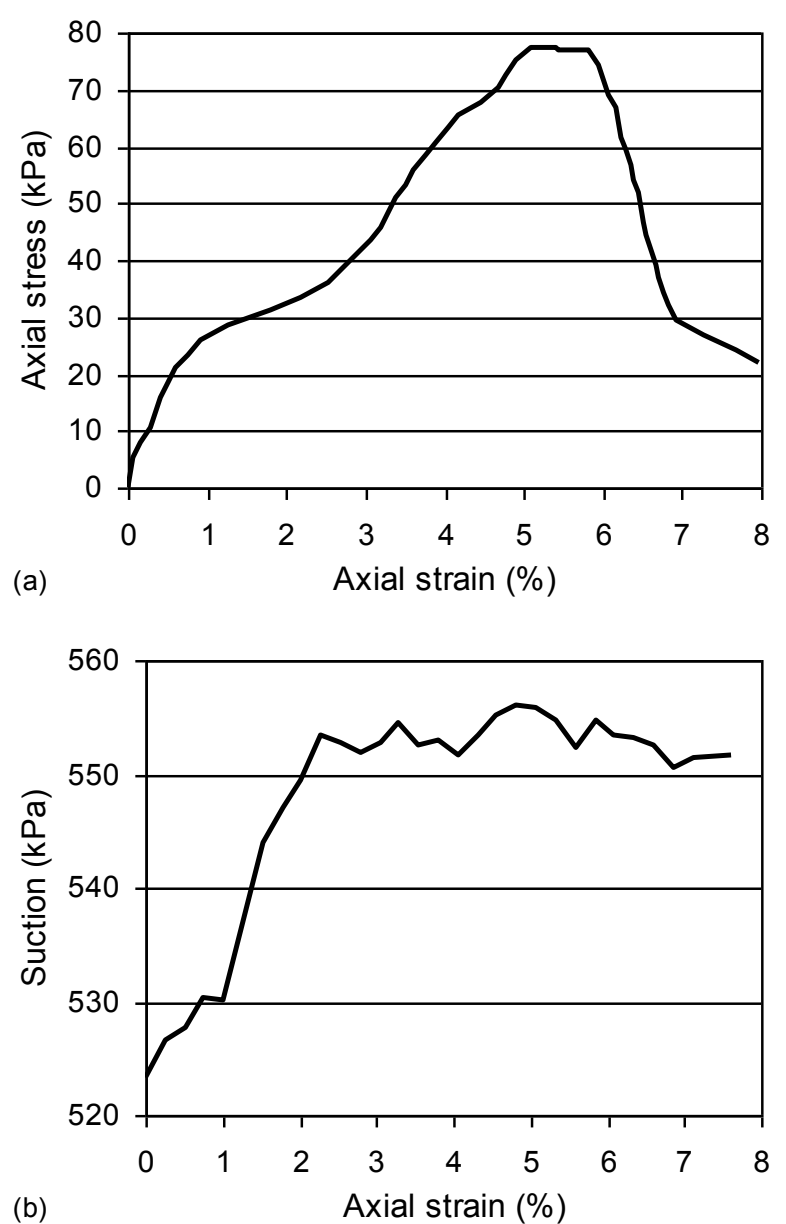

Figure 5. a) Axial stress vs axial strain, and b) suction versus axial strain during unconfined compression test on Skiros weathered Phyllite with and MPS-2 sensor installed.

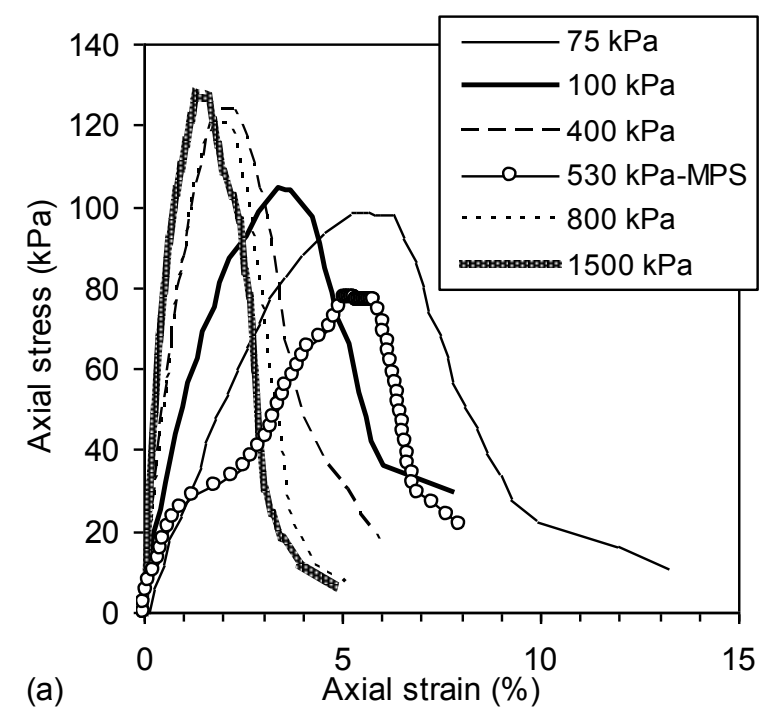

Figure 6. Axial stress vs axial strain during unconfined compression tests on Skiros weathered Phyllite for all suctions applied and for the sample with the MPS-2 sensor installed.

the crack seen at the top of the sample in Fig. 4d. This axial strain value corresponds to the beginning of a rapid suction increase in Fig. 5b. This seems to suggest that when the crack appeared some air reached the sensor leading to the suction increase observed. Therefore, the
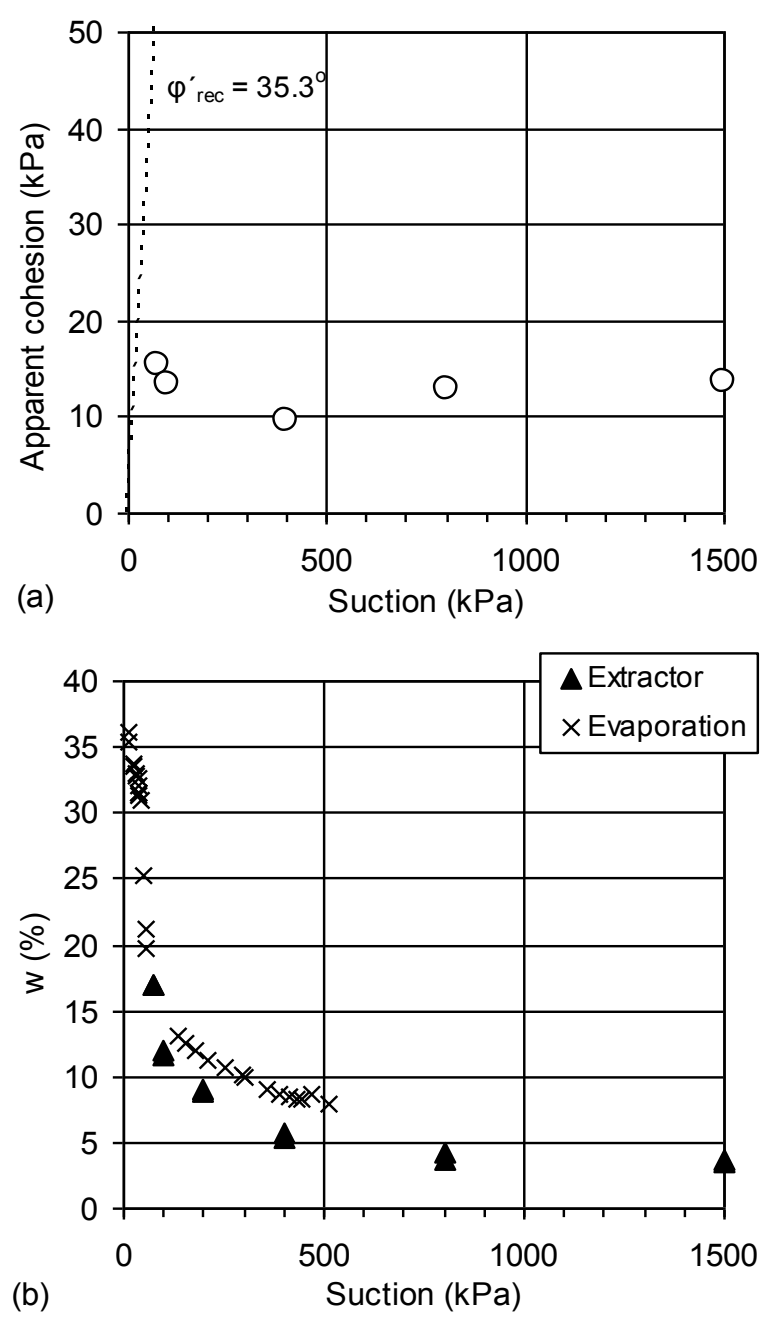

Figure 7. a) Apparent cohesion vs suction with the line corresponding to $\varphi^{\prime}$ from direct shear on slurry, and b) water content vs suction, for Skiros weathered Phyllite.

previously mentioned $7 \%$ increase could be overestimated and the actual increase of suction is probably half that. The first yield observed in the stress-strain curve is associated with the crack appearance (due to the presence of the sensor itself as the difference in the shape of the stress-strain curve of this test in comparison to all other tests without a sensor shown in Fig. 6 indicates). In conclusion, this test exhibits that the assumption that suction changes insignificantly from the end of drying until the unconfined compression test is performed is a valid one, as in the coarsest of the soils tested, the difference in suction was only $3-4 \%$. For the other soils that were more fine-grained and plastic (let alone splitting tensile tests which are quicker) this difference is anticipated to be even smaller.

\section{Unconfined compression and splitting tensile tests and their combination}

For all samples tested at each value of suction, Mohr's circles were plotted as shown in Fig. 3 (for samples of Maroussi clay under $1000 \mathrm{kPa}$ of suction) and the cohesion intercept was determined. This was then plotted vs suction for each soil along with the line corresponding to 

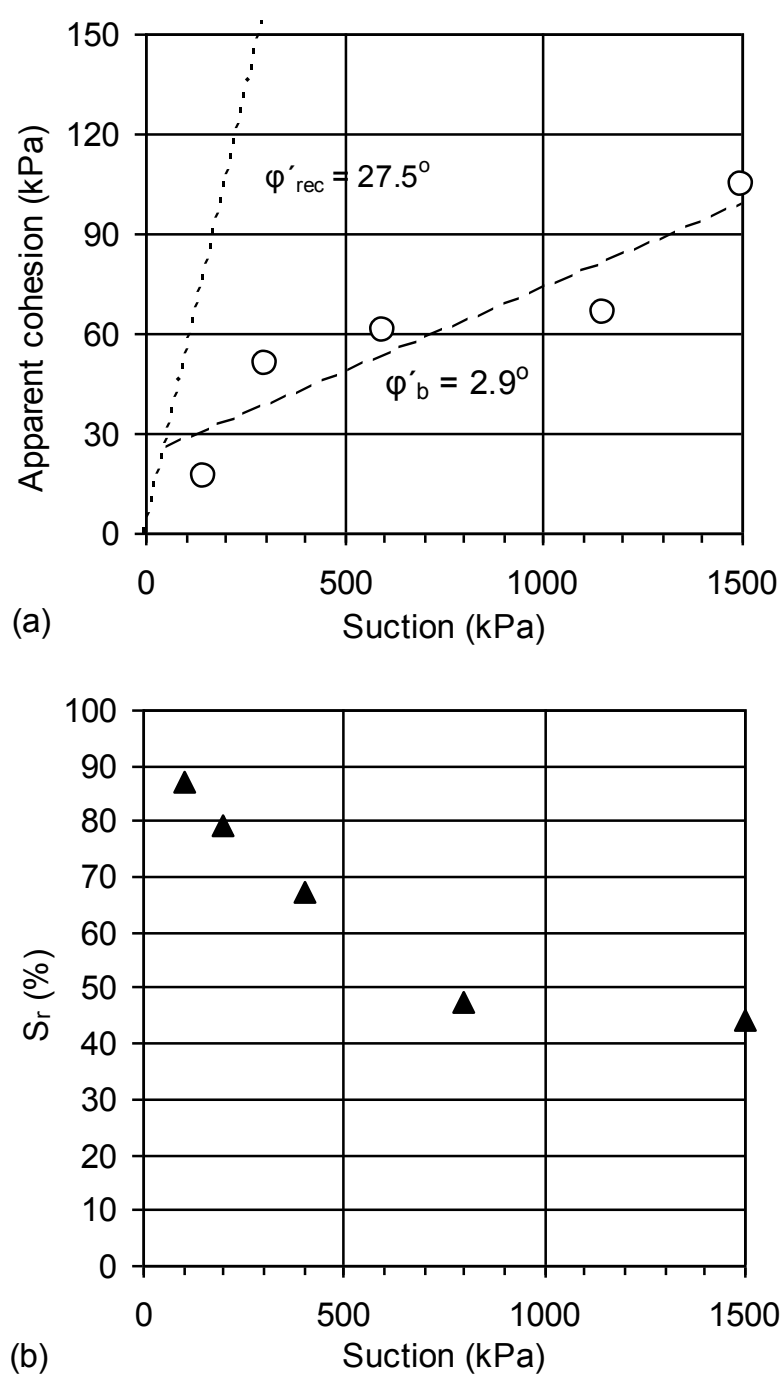

Figure 8. a) Apparent cohesion vs suction with the line corresponding to $\varphi^{\prime}$ from direct shear on slurry, and b) degree of saturation vs suction, for Corinth marl.

the angle of shearing resistance of the same soil reconstituted and fully saturated $\left(\varphi^{\prime}\right.$ rec $)$. These plots are presented in Figures 7 to 11 for Skiros weathered Phyllite, Corinth marl, Parnitha weathered siltstone, Chalkoutsi marl and Maroussi clay respectively. Figures denoted (a) present cohesion intercept vs suction, and figures denoted (b) present the part of the soil-water characteristic curve in the same range for the slurry of the soil with suction in linear scale. An exception was made for Skiros weathered Phyllite (Fig. 7) where given that the continuously monitored water content during drying from the sample with the MPS-2 sensor was available too, water content vs suction is plotted in Fig. 7b, rather than degree of saturation vs suction as in all other plots. These plots were used in accordance with the Mohr-Coulomb failure criterion for unsaturated soils [1] presented in Eq. 1, where $\mathrm{c}$ is the cohesion intercept of the fully saturated soil, $\varphi$ is the angle of shearing resistance and $\varphi_{b}$ is an angle, the tangent of which expresses the increase of strength $\tau$ with suction $\mathrm{s}$.

$$
\tau=c+\sigma \cdot \tan \varphi+s \cdot \tan \varphi_{b}
$$
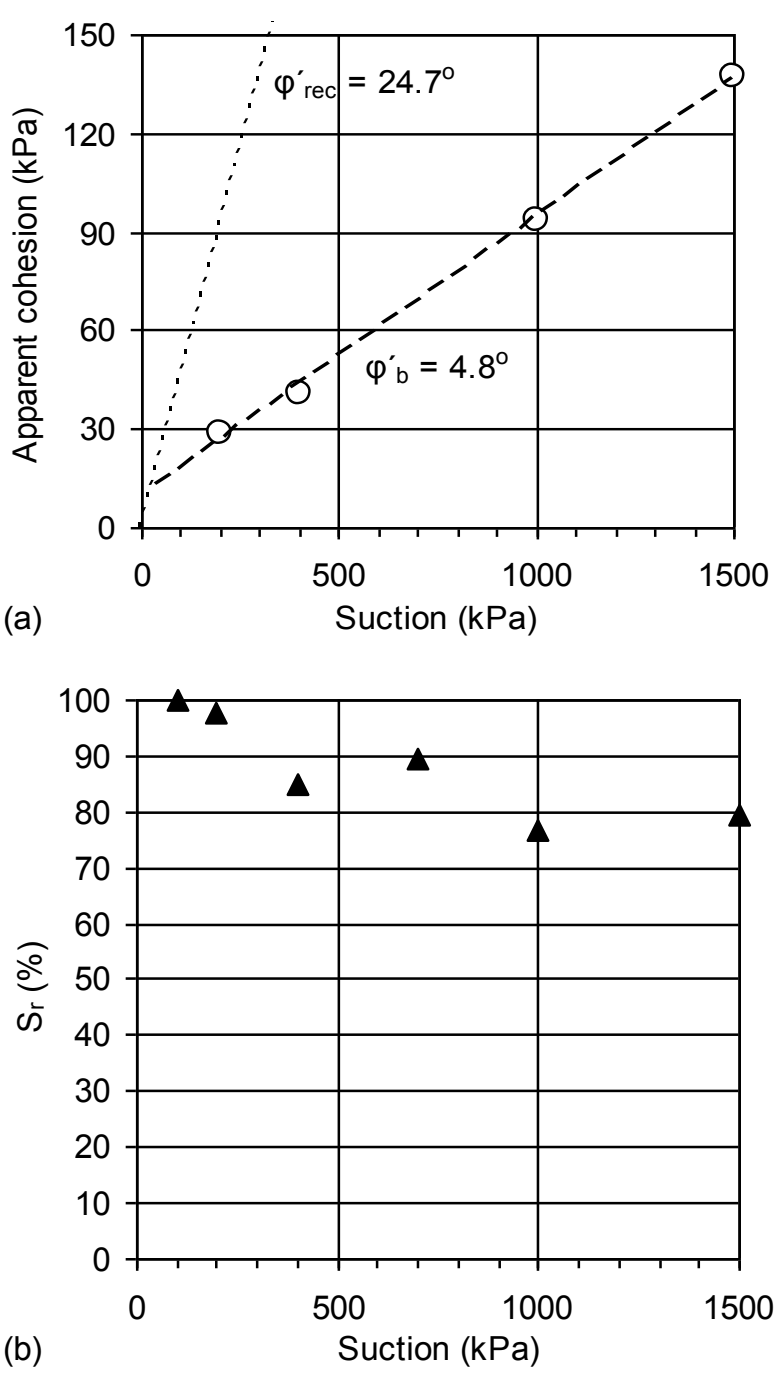

Figure 9. a) Apparent cohesion vs suction with the line corresponding to $\varphi^{\prime}$ from direct shear on slurry, and b) degree of saturation vs suction, for Parnitha weathered siltstone.

As seen in Fig. 7, Skiros weathered Phyllite desaturates at very low suction. Cohesion intercept due to suction reaches a value corresponding to the shear strength that would be obtained from the angle of shearing resistance of the fully saturated soil very close to the value corresponding to desaturation and stabilises (it may be suggested that it even decreases). In Fig. 8, Corinth marl is desaturated at $100 \mathrm{kPa}$ of suction and cohesion intercept values vs suction yield a straight line corresponding to $\varphi_{\mathrm{b}} 2.9^{\circ}$. Given that these samples were all slurries placed in the pressure extractor in plastic tubes attached to the porous plate in a manner similar to that described for the plastic tube in Fig. 4, the lowest values of suction applied had to be high enough for the samples to gain enough strength to be handled, the lowest suction applied was not sufficient for some soils to obtain accurately the suction correspondding to desaturation. One case was the Corinth marl in Fig. 8b. Still the line drawn for cohesion intercepts in Fig. 8a, intersects the line corresponding to the angle of shearing resistance of the fully saturated Corinth marl at $50 \mathrm{kPa}$, a value quite reasonable for airentry pressure given the subsequent points in Fig. 8b. Similarly, for Parnitha weathered siltstone (Fig. 9) an air- 

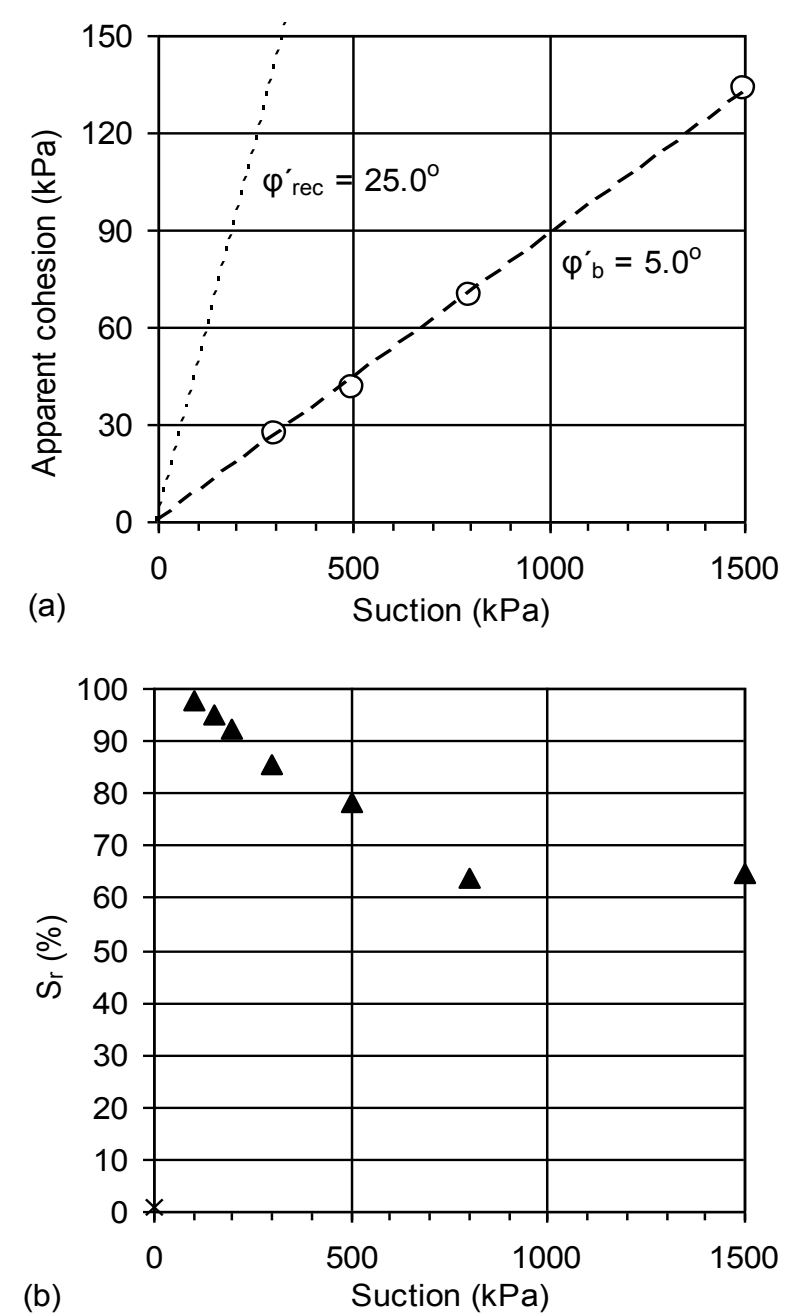

Figure 10. a) Apparent cohesion vs suction with the line corresponding to $\varphi^{\prime}$ from direct shear on slurry, and b) degree of saturation vs suction, for Chalkoutsi marl.

entry pressure of $100 \mathrm{kPa}$ was obtained at which cohesion intercept change with suction is described by a value of $\varphi_{\mathrm{b}}$ of $4.8^{\circ}$. For Chalkoutsi Marl as well (Fig. 10) an airentry pressure of less than $100 \mathrm{kPa}$ was obtained and a value of $\varphi_{b}$ of $5.0^{\circ}$. Yet this line seems to pass through zero indicating a very small value of the air entry pressure for this material in the form of slurry. Finally, for Maroussi clay (Fig. 11) air-entry pressure is higher than $1500 \mathrm{kPa}$ and as a result no straightforward interpretation of the evolution of the cohesion intercept with suction may be obtained.

\section{Conclusions}

Unconfined compression and splitting tensile tests on samples of slurries subjected to various values of suction were combined in order to obtain the cohesion intercept of these soils for various values of suction. This method yielded values of $\varphi_{b}$ in all cases except for one soil that did not desaturate in the range of suctions applied. A special test with an MPS-2 sensor installed in a sample of the coarsest and non-plastic soil during unconfined compression loading exhibited that the negligible suction change assumption behind this method is a valid one.
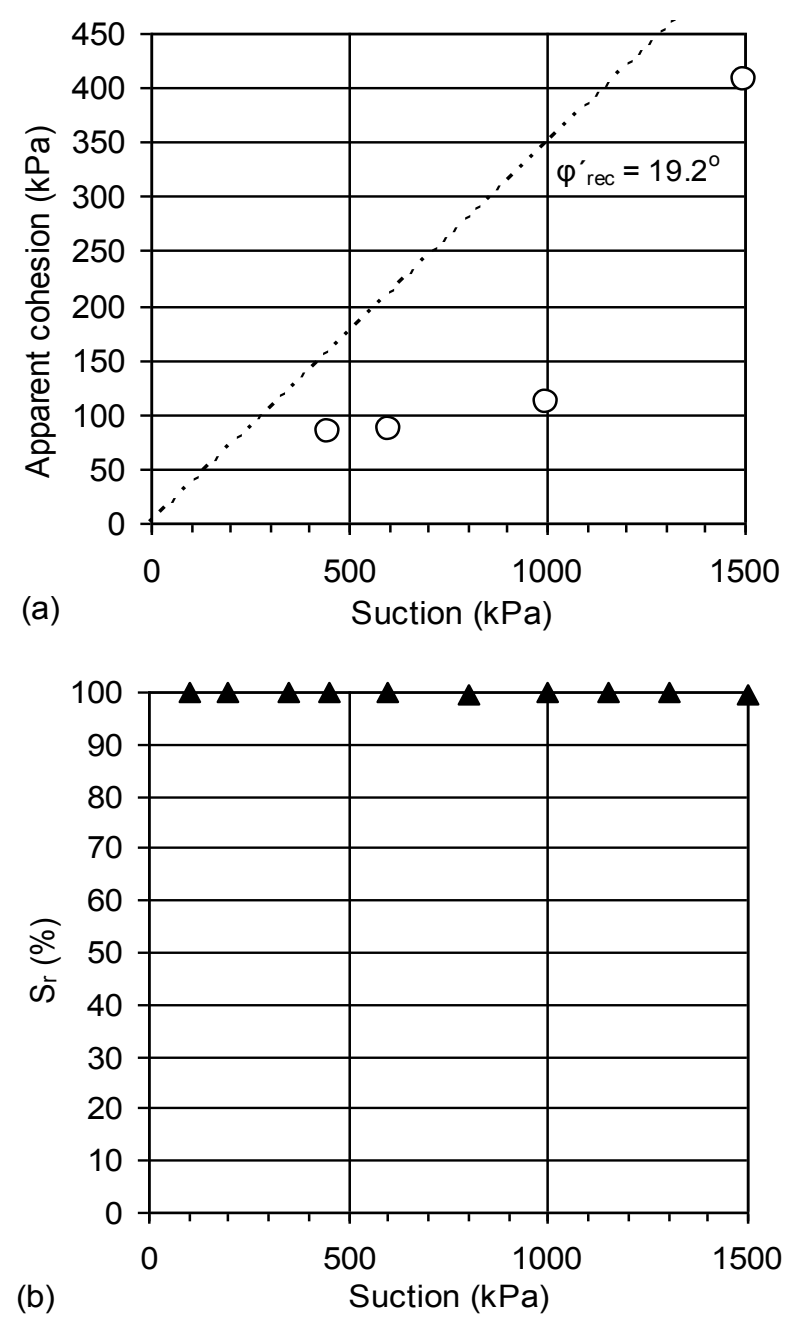

Figure 11. a) Apparent cohesion vs suction with the line corresponding to $\varphi^{\prime}$ from direct shear on slurry, and b) degree of saturation vs suction, for Maroussi clay.

\section{References}

1. D. G. Fredlund, N. R. Morgenstern, R. A. Widger, 1978, Can. Geot. J., Vol. 15, pp. 313-321

2. M. E. Bardanis, S. Grifiza, Unsaturated Soils: Research and Applications, Mancuso et al. (eds), Proc. 2nd Eur. Conf. on Unsaturated Soils, Naples, Italy, 20-22 June, 2012, Vol.1, Springer, pp. 249-256

3. M.J. Kavvadas, A.G. Anagnostopoulos, V.N. Georgiannou, M.E. Bardanis, 'Characterisation and Engineering Properties of Natural Soils', Singapore, 2002, Tan et al (eds.), 1435-1459.

4. M. E. Bardanis, M. J. Kavvadas, Unsaturated Soils: Advances in Geo-Engineering, Toll et al. (eds), Proc. 1st Eur. Conf. on Unsaturated Soils, Durham, UK, 24 July, 2008, pp. 263-269.

5. M. E. Bardanis, S. Grifiza, Proceedings of the 15 th Eur. Conf. on Soil Mechanics and Geotech. Engng, A. Anagnostopoulos et al. (eds.), IOS Press, 2011, Vol. 1, pp. 609-614.

6. G. Hondros, Aust. J. Applied Science, Vol. 10, 1959, 243. 